Original Article

\title{
Effects of simplified lymph drainage on the body: in females with menopausal disorder
}

\author{
Kazuhisa Inoue, RPT, PhD ${ }^{1 *}$, Hiroshi Maruoka, RPT, PhD ${ }^{1)}$ \\ 1) Department of Physical Therapy, Saitama Prefectural University: 820 San-Nomiya, Koshigaya-shi, \\ Saitama 343-8540, Japan
}

\begin{abstract}
Purpose] Hormone replacement therapy has been reported to be effective for alleviating menopausal symptoms, its side effects have been a concern. Therefore, it is necessary to investigate methods that could alleviate menopausal symptoms but with fewer side effects. Few previous reports have investigated the effects of simplified, viable manual lymph drainage, particularly the effects of one-time therapy on physiologically active substances and other variables. Effects of one-time simplified lymph drainage performed at salon A were investigated in females with any type of menopausal symptoms, such as edema or a sense of fatigue. [Subjects and Methods] Before and after lymph drainage, saliva was collected to detect substances that would reveal immune function. Questionnaire surveys were also conducted before and after therapy. [Results] Cortisol and dehydroepiandrosterone levels were significantly reduced after therapy compared with those before therapy. The questionnaire survey showed a significant decrease in the visual analog scale. Also apparent were positive opinions, such as "I feel better" and "My legs feel lighter." [Conclusion] These results demonstrated the stress reduction effect of one-time simplified lymph drainage, which decreased cortisol and dehydroepiandrosterone levels. This therapy was also shown to produce positive mental and physical effects.

Key words: Simplified lymph drainage, Menopausal disorder, Immune function
\end{abstract}

(This article was submitted Sep. 14, 2016, and was accepted Oct. 13, 2016)

\section{INTRODUCTION}

Various types of physical therapy have been used as means to care for the body. Manual therapy, such as massage, represents a relatively widely used therapy ${ }^{1)}$. For example, massage for edema, which is generally referred to as manual lymph drainage, is frequently performed after breast cancer surgery ${ }^{2}$. However, guidance, exercise therapy, and manual lymph drainage performed in accordance with lymphedema prevention guidelines were reported have little effect on alleviating the short-term incidence of lymphedema in patients who underwent lymph node dissection for breast cancer ${ }^{3)}$. This contradictory result warrants further investigation.

Previous studies on drainage have not provided sufficient evidence to establish a consensus because of problems with such as issues with quantification and reproducibility of manual stimuli, the diversity of procedures used for drainage, and the study designs including random allocation of subjects ${ }^{2}$. Moreover, few previous studies have addressed menopausal disorders as a targeted condition affecting lymph drainage. In one study, $57.2 \%$ of the subjects with menopausal symptoms did not seek medical advice, and 36.6\% indicated the need for personnel capable of providing appropriate treatment and psychological care for females with menopausal symptoms ${ }^{4}$. Although hormone replacement therapy has been reported to be effective for alleviating menopausal symptoms, its side effects have been a concern ${ }^{5)}$. Therefore, it is necessary to investigate methods that could alleviate menopausal symptoms but with fewer side effects.

Few previous reports have investigated the effects of simplified, viable manual lymph drainage, particularly the effects of

\footnotetext{
*Corresponding author. Kazuhisa Inoue (E-mail: inoue-kazuhisa@spu.ac.jp)

(C)2017 The Society of Physical Therapy Science. Published by IPEC Inc.

This is an open-access article distributed under the terms of the Creative Commons Attribution Non-Commercial No Derivatives (by-nc-nd) License $<$ http://creativecommons.org/licenses/by-nc-nd/4.0/>.
} 
Table 1. Saliva and VAS measurement results $(n=19)$

\begin{tabular}{lcc}
\hline Parameter & Before therapy & After therapy \\
\hline$\alpha-\mathrm{A}(\mathrm{U} / \mathrm{ml})$ & $145.3(19.4-391.3)$ & $137.1(15.1-276.8)$ \\
Corti $(\mu \mathrm{g} / \mathrm{dl})$ & $0.131(0.04-0.225)$ & $0.091(0.036-0.335)^{*}$ \\
DHEA $(\mathrm{pg} / \mathrm{ml})$ & $73.5(17.9-148.2)$ & $57.8(17.9-148.2)^{*}$ \\
SIgA $(\mu \mathrm{g} / \mathrm{ml})$ & $196.7(32.8-785.3)$ & $215.0(85.2-783.6)$ \\
VAS & $5(1-10)$ & $1(0-6)^{*}$ \\
\hline
\end{tabular}

$\alpha$-A: $\alpha$-amylase; Corti: cortsol; DHEA: dehydroepiandrosterone; SIgA: secretory immunoglobulin A; VAS: visual analog scale

Results are expressed as the median (minimum-maximum)

*Parameters that showed significant differences before and after therapy $(\mathrm{p}<0.05)$

one-time therapy on physiologically active substances and other variables ${ }^{1,6-9)}$. In this study, we examined the bodily effects of simplified lymph drainage in females with subjective menopausal symptoms.

\section{SUBJECTS AND METHODS}

The ethics committee of Saitama Prefectural University approved this study (No. 26102). The study complied with the principles of the Declaration of Helsinki. We explained the purpose and procedures of the study to the subjects and obtained their written consent.

The subjects were 20 females with any type of menopausal symptoms (e.g., edema, feeling of fatigue) who were visiting salon A. Those who were on treatment for any internal or orthopedic diseases were excluded. The subjects' enrollment was on a voluntary basis, and salon A selected the subjects.

The females underwent one-time simplified lymph drainage. The therapy involved effleurage of the whole body, including the legs, back, neck, arms, décolleté (low neck line), abdominal region, hips, and head, for a duration of 30 min. Directions of drainage were as follows: (1) upper limbs $\rightarrow$ axillary lymph nodes; (2) lower limbs $\rightarrow$ inguinal lymph nodes; (3) head; (4) neck $\rightarrow$ cervical lymph nodes; (5) lumbar/gluteal region and lower abdomen $\rightarrow$ inguinal lymph nodes. Saliva specimens were collected before and after the therapy. The subjects were also questioned about their degree of fatigue at both time points. They completed a questionnaire in regard to subjective effects at these times as well. Simplified lymph drainage was performed at salon A by certified facial estheticians from the Japan Esthetic Association.

The saliva specimens were analyzed for their $\alpha$-amylase $(\alpha-\mathrm{A}: \mathrm{U} / \mathrm{ml})$, cortisol (Corti: $\mu \mathrm{g} / \mathrm{dl})$, dehydroepiandrosterone (DHEA: pg/ml), and secretory immunoglobulin A $(\mathrm{SIgA}: \mu \mathrm{g} / \mathrm{ml})$ levels ${ }^{10-13)}$. We used a sampling device to collect the 2-ml saliva samples because it was easier to use than the conventional method with straws. After collection, the specimens were immediately transferred to storage tubes and stored in a freezer. Analysis of those specimens was performed at Funakoshi Corporation (Oga, Akita, Japan) using the Salivary EIA Kit.

A visual analog scale (VAS) was used before and after therapy to assess the degree of physical symptoms such as fatigue, and a simple questionnaire survey was conducted after therapy. The questionnaire included such subjects as changes in the body after simplified lymph drainage therapy and their feelings and thoughts after receiving the therapy. Statistical processing was performed using IBM SPSS Statistics 21 software (Armonk, NY, USA). The Wilcoxon signed rank test was used for comparisons of parameters, with a significance level of $5 \%$.

\section{RESULTS}

As a result of faulty measurements in one subject, the final study group included 19 subjects $(49.8 \pm 3.4$ years of age). Significant differences in three parameters were shown between before and after therapy (Corti, DHEA, and VAS: $p<0.05$ for all) (Table 1). Corti tended to decrease in 14 of the 19 subjects (before therapy $0.131 \mu \mathrm{g} / \mathrm{dl}$, after $0.091 \mu \mathrm{g} / \mathrm{dl}$, which is an approximately $44 \%$ decrease, $\mathrm{p}=0.044$ ). DHEA tended to decrease in 13 of the 19 subjects (before $73.5 \mathrm{pg} / \mathrm{ml}$, after $57.8 \mathrm{pg} / \mathrm{ml}$, which is an approximately $27 \%$ decrease, $\mathrm{p}=0.018$ ). After therapy, the VAS scores for the degree of pain after therapy were significantly reduced $(\mathrm{p}=0.001)$, the $\alpha$-A concentration was reduced (in 12 of 19 subjects, $p=0.546)$, and the SIgA concentration was increased (in 12 of 19 subjects, $p=0.184)$. Neither of the latter two measurement differences $(\alpha$-A or SIgA reached statistical significance. Finally, the results of the after-therapy questionnaire indicated that all 19 subjects had positive opinions about undergoing one-time simplified lymph drainage: "I feel that my body is warmer," "I feel that my body is lighter," "I felt it was good for my health." Two of the subjects, however, stated that the therapy was painful.

\section{DISCUSSION}

The effects of simplified lymph drainage on the body indicated that Corti and DHEA decreased after therapy by $44 \%$ and 
27\%, respectively. Increased Corti secretion was due to enhanced activation of the cerebrum-hypothalamus-pituitary-adrenal cortex pathway, which occurs when it is subjected to acute stress, resulting in an elevated blood glucose level. Corti also adjusts the balance of various substances, allowing the human body to tolerate stress. When enhanced secretion of Corti is prolonged, however, the body becomes exhausted and develops disorders often referred to as "stress disease." This condition then leads to more production of Corti ${ }^{11)}$.

DHEA, a steroid hormone that is mainly produced in the adrenal gland, is known for its anti-glucocorticoid, antioxidant, anti-inflammatory, and immunomodulatory actions, among others. DHEA production increases under stressful conditions, being affected by the activities of the hypothalamus-pituitary-adrenal cortex system and adrenocorticotropic hormone. A stress-responsive substance associated with Corti, DHEA is considered to be a marker of tissue repair. Tissues that were damaged by increased Corti and catecholamine due to stress stimuli are thought to be repaired by the action of DHEA, whose secretion is induced by a subsequently secreted assimilative factor (i.e., insulin). Therefore, as DHEA and Corti are increased by stress stimuli, their decreased levels after therapy were thought to result from the significantly reduced stress to the body. It is presumed that significant differences were noted for these substances because they are interrelated.

In contrast, no significant differences were observed in the before and after therapy measurements of $\alpha$-A or SIgA. Pain stimulation might have been a factor for the low impact of therapy on immune function as the questionnaire results indicated that some of the subjects experienced pain during the therapy.

According to the VAS scores, simplified lymph drainage had a positive effect on physical symptoms such as fatigue. The VAS scores before and after therapy indicated a significant decrease in the degree of fatigue. Although the questionnaire survey indicated that there were two subjects who experienced slight pain during the therapy, it was assumed not to have a significant impact on the degree of fatigue. Moreover, most subjects reported that the therapy warmed their body, which could be because it improved the blood circulation, resulting in a hyperthermic effect and reduced fatigue.

Massage has been reported to have effects such as reducing fatigue, preventing a decline in exercise performance, and preventing delayed onset of muscle soreness ${ }^{6}$. Massage also is known to decrease muscle tone, reduce edema, promote circulation and metabolism, and improve immune function ${ }^{7}$. An advantage of massage is that it is done manually and does not require specific devices or places for practice. It can be applied to one's own body by learning certain techniques and methods because it is minimally invasive and relatively safe. The relaxation effect of massage for relieving psychological stress has also been reported ${ }^{8}$. Thus, massage is expected to be an effective method for removing various negative effects such as fatigue and stress.

The tactile pressure stimulus on the skin surface during massage is recognized through sensory receptors transmitted from the spinal cord, via the medulla oblongata and the diencephalon, to the cerebral cortex. The stimulus is then transmitted from the cerebral cortex to the hypothalamus (acting as an information control) and ultimately affecting autonomic nerves, the endocrine system, and immune function. Interactions among these biological reactions harmonize the activities of the living body and produce antagonistic actions as stress reactions. Ko et al. ${ }^{14)}$ performed combination therapy with lymph drainage, application of an elastic bandage, and exercise for patients with lymphedema. They reported significant alleviation of lymphedema.

Although it has been reported that manual lymph drainage has a facilitatory effect on regional circulation in skin and subcutaneous tissues $^{7}$, another report indicated that there were no significant changes in blood circulation before and after drainage $^{9)}$. Thus, further investigation on the effects of this therapy on lymphedema is required. Swelling of connective tissues and decreased separation of muscle fibers are observed with lymphedema. In such cases, manual lymph drainage has been reported to enhance tissue healing because of its ability to reduce muscle fiber separation and fibrous thickening of the blood vessel wall ${ }^{15}$. Furthermore, back massage of healthy individuals has been reported to have potentially beneficial effects on immune function by increasing salivary chromogranin-A. The results of the present study are consistent with those of that study ${ }^{16)}$.

A limitation of the present study is that it did not involve a control group. Therefore, further investigation using a control group is required.

\section{REFERENCES}

1) Tiidus PM: Manual massage and recovery of muscle function following exercise: a literature review. J Orthop Sports Phys Ther, 1997, 25: 107-112. [Medline] [CrossRef]

2) Kimura T: Basics of massage. Rigakuryoho, 2002, 19: 381-388.

3) Devoogdt N, Christiaens MR, Geraerts I, et al.: Effect of manual lymph drainage in addition to guidelines and exercise therapy on arm lymphoedema related to breast cancer: randomised controlled trial. BMJ, 2011, 343: d5326. [Medline] [CrossRef]

4) Saudi TO: Menopause as a transitional period of life. Ritsumeikan Soc Sci Rev, 2002, 38: 45-62.

5) Ouchi Y, Inoue S, Misaki M, et al.: Comprehensive study on hormone replacement therapy for the health promotion of elderly females. Health and Labour Sciences Research Report. https://mhlw-grants.niph.go.jp/niph/search/NIDD00.do?resrchNum=200000186A (Accessed Apr. 22, 2016)

6) Ernst E: Does post-exercise massage treatment reduce delayed onset muscle soreness? A systematic review. Br J Sports Med, 1998, 32: 212-214. [Medline] [CrossRef] 
7) Braverman DL, Schulman RA: Massage techniques in rehabilitation medicine. Phys Med Rehabil Clin N Am, 1999, 10: 631-649, ix. [Medline]

8) Rexilius SJ, Mundt C, Erickson Megel M, et al.: Therapeutic effects of massage therapy and handling touch on caregivers of patients undergoing autologous hematopoietic stem cell transplant. Oncol Nurs Forum, 2002, 29: E35-E44. [Medline] [CrossRef]

9) Shoemaker JK, Tiidus PM, Mader R: Failure of manual massage to alter limb blood flow: measures by Doppler ultrasound. Med Sci Sports Exerc, 1997, 29: 610-614. [Medline] [CrossRef]

10) Chatterton RT Jr, Vogelsong KM, Lu YC, et al.: Salivary alpha-amylase as a measure of endogenous adrenergic activity. Clin Physiol, 1996, 16: 433-448. [Medline] [CrossRef]

11) Kirschbaum C, Hellhammer DH: Salivary cortisol in psychoneuroendocrine research: recent developments and applications. Psychoneuroendocrinology, 1994, 19: 313-333. [Medline] [CrossRef]

12) Mestecky J: Saliva as a manifestation of the common mucosal immune system. Ann N Y Acad Sci, 1993, 694: 184-194. [Medline] [CrossRef]

13) Hucklebridge F, Lambert S, Clow A, et al.: Modulation of secretory immunoglobulin A in saliva; response to manipulation of mood. Biol Psychol, 2000, 53: 25-35. [Medline] [CrossRef]

14) Ko DS, Lerner R, Klose G, et al.: Effective treatment of lymphedema of the extremities. Arch Surg, 1998, 133: 452-458. [Medline] [CrossRef]

15) Wood EC: Beard's massage; principles and techniques. Philadelphia: W.B. Saunders, 1974, pp 50-55.

16) Noto Y, Kudo M, Sato T, et al.: Effects of back massage on phyohological status and salivary biomarkers. Hirosaki Med J, 2007,59 (Suppl.): S188-S192. 